\title{
Prediction of Compressive Strength of Calcined Clay Based Cement Mortars Using Support Vector Machine and Artificial Neural Network Techniques
}

\author{
Joseph Mwiti Marangu ${ }^{1, *}$ \\ ${ }^{1}$ Department of Physical Sciences, Meru University of Science and Technology-Meru, Kenya
}

Manuscript Received September 12, 2019; Accepted March 29, 2020

\begin{abstract}
Prediction of strength in cement based materials is vital in construction industry as it forms the basis upon which important tasks can be performed such as the time for mortar form removal, project scheduling and quality control among others. The paper reports both experimental and simulated findings on compressive strength of laboratory prepared blended cement mortars. The blended cement was prepared by blending calcined clays with Ordinary Portland Cement (OPC) at replacement levels ranging from $35 \%$ to $50 \%$ by mass of OPC. In the experimental approach, mortars measuring $160 \mathrm{~mm} \times 40 \mathrm{~mm} \times 40$ $\mathrm{mm}$ were cast using the blended cement at a water to cement $(\mathrm{w} / \mathrm{c})$ ratio of $0.40,0.50$ and 0.60 separately and cured for 2,7 and 28 days in a laboratory set-up. Compressive strength measurements were taken at each of the curing ages. Part of the experimental data obtained was used to train both Support Vector Machine (SVM) and Artificial Neural Network (ANN) models while the other was used in validation of the models. The trained models were used to predict the 28 day compressive strengths at w/c of 0.35 and 0.65 and also at a cement replacement of greater than $50 \%$ and also less than $35 \%$. The results showed that in training and testing, ANN exhibited stronger potential for predicting compressive strength at w/c of 0.35 and w/c of 0.65 than SVM. In addition, ANN was further found to give more accurate prediction of compressive strength than SVM at all the percentage replacement ranging from 0-60\% with calcined clays. In conclusion, the testing performance of both SVM and ANN was 0.88 and 0.95 respectively.
\end{abstract}

Keywords: Artificial Neural Network; Blended Calcined Clay; Cement; Compressive Strength; Pozzolana; Support Vector Machine

\section{Introduction}

The infrastructural development forms a critical component of most national economies globally. The overall performance of cement materials largely depends on the strength development of cement materials. Experimental determination of compressive strength is a time consuming and expensive especially where long curing ages and high pozzolana replacements are involved majorly in blended cements. Therefore, there is need for application of robust techniques that accurately predicts the strength characteristics of different formulations of blended cements where several pozzolana replacements are incorporated.Machine Learning (ML) is a branch of artificial intelligence concerned in development of predictive models without explicitly programming a computer. The predictive model is derived by learning algorithms that search for hidden structure and patterns in the training set data. The inherent patterns in different classes of data aid in developing a mathematical function

${ }^{*}$ Corresponding author:

E-mail address: jmarangu2011@gmail.com (J. Marangu)

https://doi.org/10.29187/jscmt.2020.43 
(predictive model) that maps a set of input data to the corresponding target output. ML can be broadly classified into two categories namely supervised and unsupervised learning. In supervised learning, labeled input data and target output is used by a learning algorithm to develop a predictive model while as in unsupervised learning the learning ${ }^{\dagger}$ algorithm figures out the similarities and differences in the presented unlabeled data with an aim of clustering the data based on their structure. Artificial Neural Networks (ANN) and Support Vector Machine (SVM) are two approaches used in supervised machine learning. SVM figures out higher dimensional planes (hyper-planes) that separate different classes of data in a training set. On the other hand, ANN attempts to explore a non-linear mathematical relationship that maps the input data to the corresponding target output. SVM has been outperforming ANN in machine learning tasks until recently when the concept of deep learning was introduced [1]. Deep learning entails using a learning algorithm to implicitly figure out suitable feature vectors to be used in training of the model as well as in prediction using a pre-trained model [2], [3]. ML has been successfully applied in many areas including; computer vision [4], speech recognition[5], natural language processing[6], stock and real estate market forecasting [7]among many other sectors. A limited number of published papers aimed at applying ML in foresting the strength of cement materials at different curing stages have been reported[8]. The performance of cement based materials is largely determined by the compressive strength development of the hydrated cement[9],[10]. Accurate prediction of compressive strength is therefore crucial since it is a key parameter during design and construction[11]-[14]. The present study aimed to investigate the performance of ANN vis a vis SVM in predicting the compressive strength of blended cements containing high content calcined clay as pozzolana and water/cement (w/c) ratio.

\section{Materials and Methods}

\subsection{Materials}

OPC $\left(42.5 \mathrm{~N} / \mathrm{mm}^{2}\right)$ was used in the study. Raw clay obtained from Embu County in Kenya was calcined at $800{ }^{\circ} \mathrm{C}$ for four hours in an electrical Muffle furnace. The resultant clay was cooled and finely ground using a laboratory ball mill to achieve $90 \mu \mathrm{m}$ sizes. Requisite amounts of calcined clay and OPC were mechanically mixed to make the test blended cement at 25, 30, 35, 40, 45 and 50 per cent substitution of OPC. Standard sand was used for mortar preparation. The chemical composition of calcined clay used is shown in Table 2

Table 2: Chemical Composition of Calcined Clay

\begin{tabular}{lccccccccc}
\hline Oxide & $\mathrm{SiO}_{2}$ & $\mathrm{Al}_{2} \mathrm{O}_{3}$ & $\mathrm{Fe}_{2} \mathrm{O}_{3}$ & $\mathrm{CaO}$ & $\mathrm{MgO}$ & $\mathrm{K}_{2} \mathrm{O}$ & $\mathrm{Na}_{2} \mathrm{O}$ & $\mathrm{TiO}_{2}$ & $\mathrm{LOI}$ \\
\hline$\%$ Composition & 58.4 & 13.6 & 10.5 & 0.4 & 1.7 & 2.9 & 4.1 & 3.1 & 3.0 \\
\hline
\end{tabular}

\subsection{Methods}

\subsubsection{Compressive Strength Determination}

The mortars were prepared using a laboratory made blended cement that incorporated calcined clay at different substitutions of Ordinary Portland Cement (OPC) in the range of 30-50\% by mass of OPC. The mortars were cast at a water to cement (w/c) ratio of $0.40,0.50$ and 0.60 separately and cured for 2,7 and 28 days in a laboratory set-up. At each of the curing ages, an average of triplicate measurement taken was used as the final Compressive strengths for the mortars.

\subsubsection{Machine Learning}

The 2, 7 and 28 days laboratory data was processed before it was fitted to the model. This involved selecting the sample size $\mathrm{n}$. In the present study a sample size of 53 was selected. The data was then split into training and testing set based on train test split library available in scikit-learn machine learning library which randomly splits the data using stratification. The split was $80 \%$ for the training set and $20 \%$ for the testing/validation set. Support Vector Machine (SVM) is a machine learning algorithm focused on modern statistical theory[14], [15]. The implementation was a regression problem and support vector regression was selected. The objective of SVM is 
to find a hyperplane in a $\mathrm{N}$-dimensional space ( $\mathrm{N}$ - number of samples) that distinctly classifies the data points. The implemented SVM had the following parameter values; kernel=linear, regularization parameter $=1$, degree of polynomial kernel function $=3$.

Artificial Neural Network (ANN) are set of algorithms modelled after the human brain, designed to recognize patterns[16], [17]. It maps inputs to outputs by finding correlations, because it can learn to approximate an unknown function $\mathrm{f}(\mathrm{x})=\mathrm{y}$ between any input $\mathrm{x}$ and output $\mathrm{y}$. In the process of learning, a neural net finds the right $\mathrm{f}$, or the correct manner of transforming $\mathrm{x}$ into $\mathrm{y}$.

The implemented ANN was made of 5 layers; one input, one output layer and three hidden layers. It involved passing a rectifier function at each layer; relu (rectified linear unit) was selected for this case. The number of nodes/neurons in the input layer was 128 and for the subsequent hidden layers were 256. The node for the output layer was one since it is a regression problem. Mean absolute error loss and Adam optimizer were used when compiling the model. The summary of the description of ANN Model used is shown in Table 3.

Table 3: Descriptive Summary of ANN Model Used.

\begin{tabular}{lll}
\hline Layer (type) & Output Shape & Param \# \\
\hline Dense_15 (Dense) & (None, 256) & 512 \\
Dense_16 (Dense) & (None, 256) & 33024 \\
Dense_17 (Dense) & (None, 256) & 65792 \\
Dense_18 (Dense) & (None, 256) & 65792 \\
Dense_19 (Dense) & (None, 1) & 257 \\
Total params: 165,337 & & \\
Trainable params: 165,377 & & \\
Non-trainable params: 0 & & \\
\end{tabular}

\section{Result and Discussion}

\subsection{Laboratory Results}

Table 4 shows the compressive strength results obtained from the laboratory set-up at different replacements of OPC with calcined clays at w/c 0.40, 0.5 and 0.6 separately.

Table 3 (a): Compressive Strength Results from Laboratory set-up Measurements

\begin{tabular}{|c|c|c|c|c|}
\hline \multirow[b]{2}{*}{$\mathrm{w} / \mathrm{c}$} & \multirow{2}{*}{$\begin{array}{l}\text { Percentage } \\
\text { Replacement }(\%)\end{array}$} & \multicolumn{3}{|c|}{ Compressive Strength (MPa) } \\
\hline & & 2 (Days) & 7 (Days) & 28 (Days) \\
\hline \multirow{6}{*}{0.4} & 0 & 24.32 & 36.09 & 48.75 \\
\hline & 30 & 18.27 & 28.68 & 41.70 \\
\hline & 35 & 16.43 & 26.41 & 39.99 \\
\hline & 40 & 14.32 & 24.32 & 36.33 \\
\hline & 45 & 12.44 & 22.36 & 34.02 \\
\hline & 50 & 10.53 & 21.07 & 31.78 \\
\hline \multirow{6}{*}{0.5} & 0 & 20.33 & 32.1 & 44.76 \\
\hline & 30 & 14.28 & 24.69 & 36.82 \\
\hline & 35 & 12.44 & 22.42 & 35.17 \\
\hline & 40 & 10.33 & 20.33 & 32.4 \\
\hline & 45 & 8.45 & 18.37 & 30.48 \\
\hline & 50 & 6.54 & 17.08 & 28.37 \\
\hline \multirow{6}{*}{0.6} & 0 & 17.89 & 29.66 & 42.32 \\
\hline & 30 & 11.84 & 22.25 & 34.56 \\
\hline & 35 & 10 & 19.98 & 33.80 \\
\hline & 40 & 7.89 & 17.89 & 29.72 \\
\hline & 45 & 6.01 & 15.93 & 27.51 \\
\hline & 50 & 4.1 & 14.64 & 25.83 \\
\hline
\end{tabular}


It was observed that addition of calcined clays to OPC resulted to progressive reduction in compressive strength at 28 days. This can be attributed to the reduction in the amount of clinker phases $\left(\mathrm{C}_{2} \mathrm{~S}\right.$ and $\left.\mathrm{C}_{3} \mathrm{~S}\right)$ that are mainly responsible for strength development in hydrated mortars. Hydration of $\mathrm{C}_{2} \mathrm{~S}$ and $\mathrm{C}_{3} \mathrm{~S}$ results in the formation of CSH as shown in Equation (1) and (2) [18].

$$
\begin{aligned}
& \mathrm{C}_{3} \mathrm{~S}+\mathrm{H} \rightarrow \mathrm{CSH}+2 \mathrm{CH} \\
& \mathrm{C}_{2} \mathrm{~S}+2 \mathrm{H} \rightarrow \mathrm{CSH}+\mathrm{CH}
\end{aligned}
$$

CSH impart strength in cementitious materials. There was an increase in compressive strength with increased curing age. This can be attributed to the continued hydration reaction as indicated by equation (1) and (2) Moreover, in case of the substituted blends at 30-50\% with calcined clays, pozzolan reaction. During the pozzolana reaction, amorphous silica $(\mathrm{S})$ and alumina $(\mathrm{A})$ with $\mathrm{CH}$ formed during hydration of $\mathrm{C}_{2} \mathrm{~S}$ and $\mathrm{C}_{3} \mathrm{~S}$ to form more CSH as shown by Equation (3) and (4) [19].

$$
\begin{aligned}
& \mathrm{CH}+\mathrm{S}+\mathrm{H} \rightarrow \mathrm{CSH} \\
& \mathrm{CH}+\mathrm{A}+\mathrm{H} \rightarrow \mathrm{CAH}
\end{aligned}
$$

$\mathrm{CAH}$ and $\mathrm{CSH}$ formed in equation (3) and (4) are also cementious and they impart more strength to the cement mortars albeit at longer curing ages [9].

Increase in the amount of calcined clays form 0-50\% resulted in progressive decrease in strength. This implies that the replacement of OPC with calcined clays results in progressively decrease in the amount of CSH formed hence lowering the strength of the mortars. This shows that in highly substituted blended cements, the added calcined clay was only served as filler material within the hydrated cement matrix rather than acting as a cementitious material. However, shown in table, strength increased with increasing age which indicated the presence of pozzolanic reaction.

At each of the substitution level, compressive strength compressive strength was observed to decrease with increased $w / c$ in the order $0.4>0.5>0.6$. This can be attributed to the facts that increase in w/c increases the porosity of the resulting mortars which subsequently lowers their compressive strength.

\subsection{Laboratory versus Modelled Compressive Strength Results}

The laboratory measurements of strength were taken as the true / accurate compressive strength and used as the reference to evaluate the strength values predicted by SVM and ANN models. The 28 - day laboratory verses modelled compressive strength results are shown in Figure (1-3) at w/c 0.4, 0.5 and 0.6 separately.

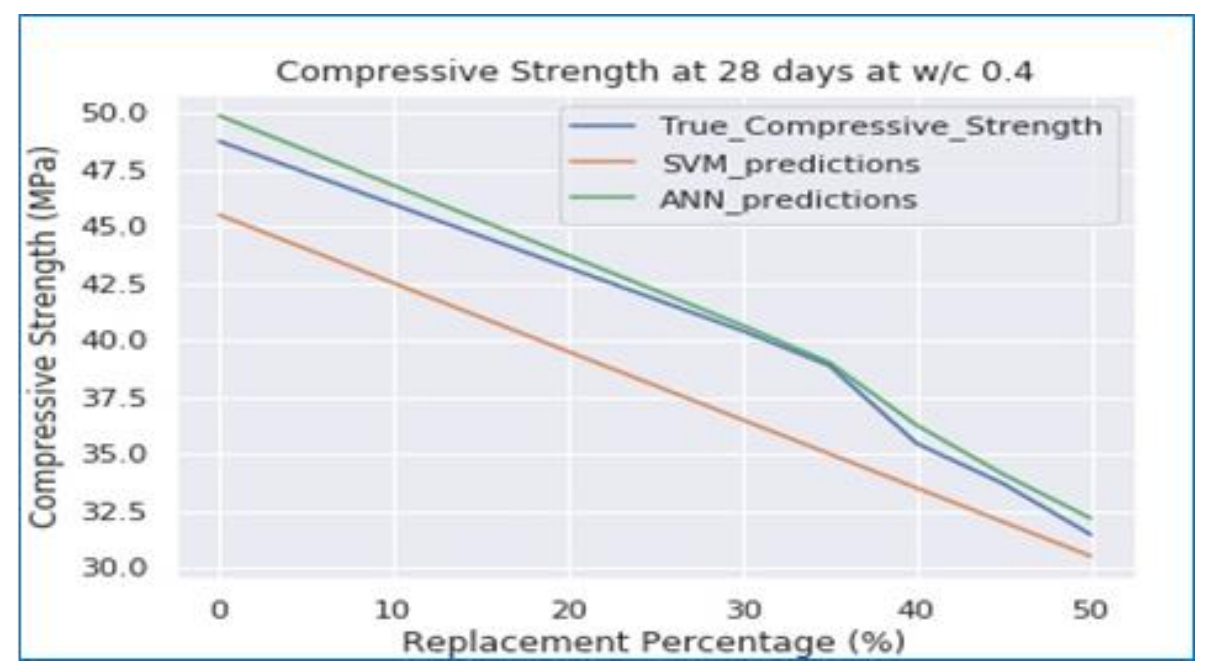

Figure 1: Laboratory verses Modelled Compressive Strength Results (w/c 0.4) 


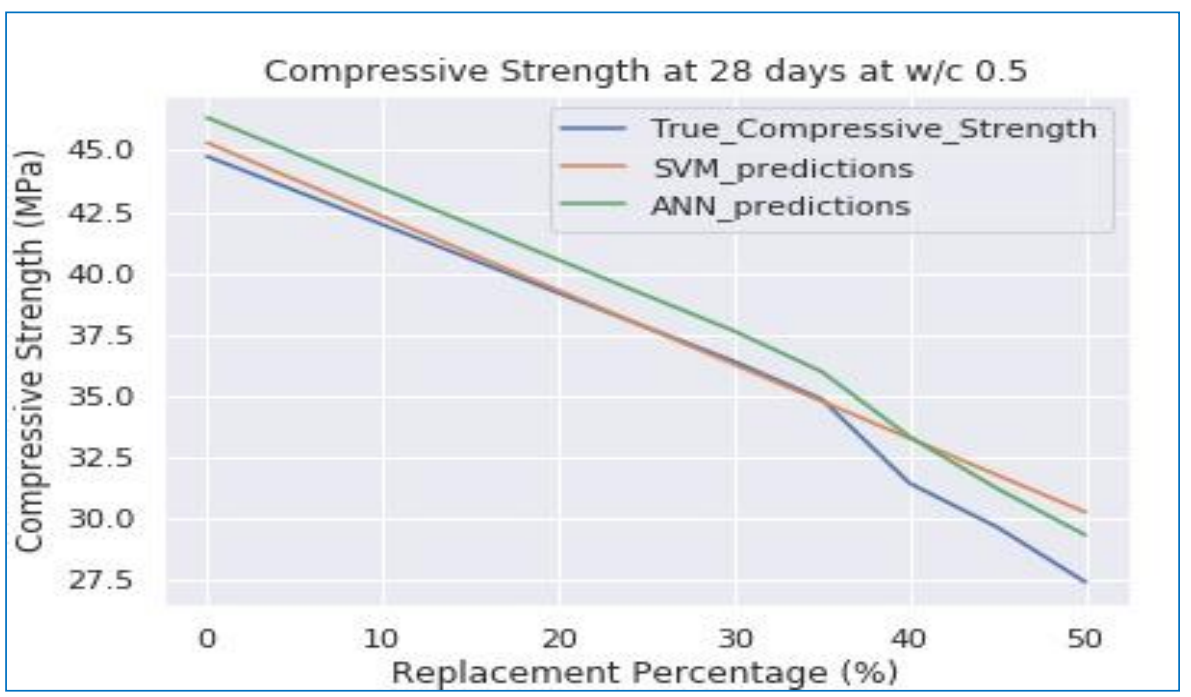

Figure 2: Laboratory verses Modelled Compressive Strength Results (w/c 0.5)

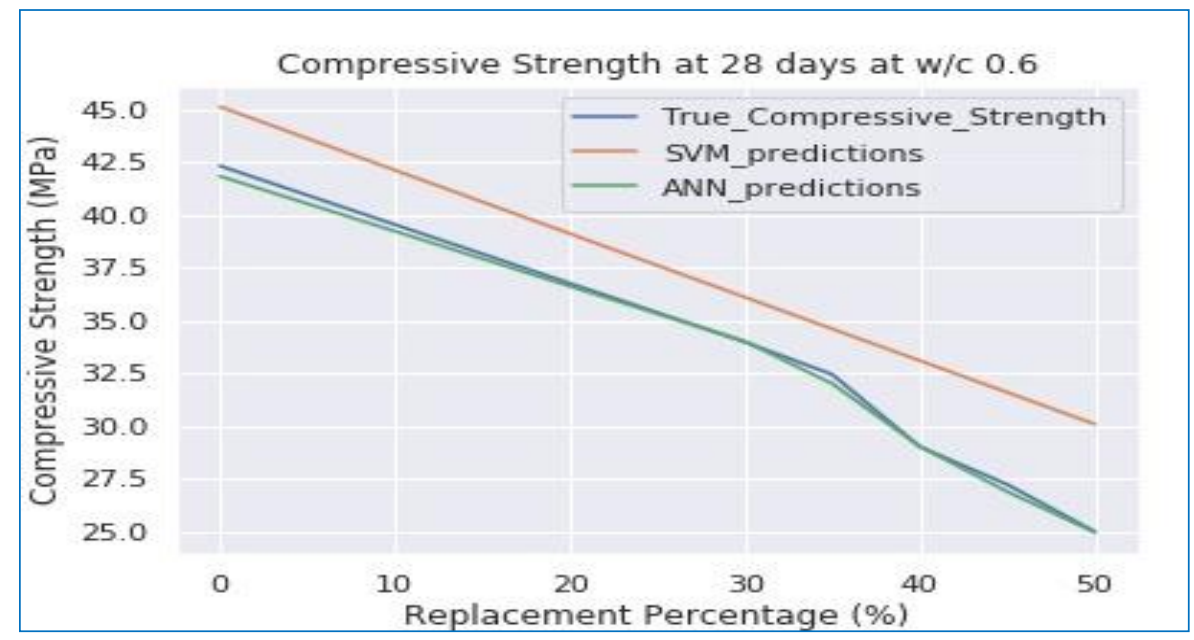

Figure 3: Laboratory verses Modelled Compressive Strength Results (w/c 0.6)

Based on Figure 1, at w/c $=0.4$, the compressive strength values predicted by the ANN model were closer to the experimental values at all replacement percentages than SVM.

In addition, from Figure 2, at w/c $=0.5$, the compressive strength values predicted by the SVM model were closer to the experimental values than ANN at replacement percentages less than $35 \%$. At replacement level greater than $35 \%$, the compressive strength values predicted by ANN model were closer to the experimental values than SVM.

Moreover, from Figure 3, at w/c $=0.6$, the compressive strength values predicted by the ANN model were closer to the experimental values at all replacement percentages than SVM. In conclusion, it was noted that ANN model was more accurate in prediction of compressive strength for clay based cement where w/c is less than 0.5 or greater than $0.5(\mathrm{w} / \mathrm{c}<0.5<\mathrm{w} / \mathrm{c})$ at clay substitution levels considered. The testing performance of both SVM and ANN was 0.88 and 0.95 respectively.

\subsection{ANN Model Predicted Compressive Strength (At 28 Day)}

The 28- day compressive strength predicted by ANN model at different percentages of replacements with calcined clays is presented in Table 3 (b) in the grey shaded region. 
Table 3(b): ANN Model Predicted Compressive Strengths (At 28 Days)

\begin{tabular}{|c|c|c|c|c|c|}
\hline \multirow{2}{*}{$\begin{array}{l}\text { Percentage } \\
\text { Replacement (\%) }\end{array}$} & \multicolumn{5}{|c|}{ Compressive Strength (MPa) } \\
\hline & $\mathrm{w} / \mathrm{c}=0.35$ & $\mathrm{w} / \mathrm{c}=0.40$ & $\mathrm{w} / \mathrm{c}=0.50$ & $\mathrm{w} / \mathrm{c}=0.60$ & $\mathrm{w} / \mathrm{c}=0.65$ \\
\hline 0 & 52.73 & 50.94 & 47.36 & 44.89 & 44.13 \\
\hline 5 & 47.71 & 46.71 & 42.87 & 40.94 & 40.07 \\
\hline 10 & 46.14 & 44.52 & 41.63 & 39.74 & 38.86 \\
\hline 15 & 44.58 & 43.89 & 39.95 & 38.05 & 37.15 \\
\hline 20 & 43.3 & 42.98 & 38.34 & 36.42 & 35.51 \\
\hline 25 & 42.48 & 41.86 & 37.90 & 35.01 & 34.04 \\
\hline 30 & 42.98 & 41.70 & 36.82 & 34.56 & 33.69 \\
\hline 35 & 41.95 & 39.99 & 35.17 & 33.80 & 32.55 \\
\hline 40 & 38.29 & 36.33 & 32.4 & 29.72 & 28.46 \\
\hline 45 & 35.87 & 34.02 & 30.48 & 27.51 & 26.47 \\
\hline 50 & 33.67 & 31.78 & 28.37 & 25.83 & 24.84 \\
\hline 55 & 32.51 & 30.79 & 27.78 & 25.18 & 24.75 \\
\hline 60 & 32.47 & 29.85 & 26.93 & 24.82 & 24.4 \\
\hline
\end{tabular}

The ANN model was used to estimate the compressive strength values at 5-25\% replacement of OPC with calcined clays. From the predicted results (in the grey shaded region of table 3(b), it was noted that regardless of the w/c ratio used, the compressive strength decreased with increase in addition of calcined clay added. This observation is consistent with other experimental observations. It is justified because as the replacement percentage is increased, surface area of filler material to be bonded by cement increases thereby reducing strength progressively[20].

The predicted compressive results further show that as w/c increases, compressive strength decreases markedly. This observation is in agreement with the experimental findings. When high w/c is involved, there is a poor packing of cement grains and aggregates which makes the hydrated cement matrix more porous[21]-[23]. Increased porosity of hydrated cement subsequently results in reduced compressive strength of the cement based structure.

\section{Conclusion}

Based on the study, ANN was found to give more accurate prediction of compressive strength than SVM at all the percentage replacement ranging from 0-60\% with calcined clays. The testing performance of both SVM and ANN was 0.88 and 0.95 respectively.

\section{Funding}

This work this work did not receive any external research grant or funding.

\section{References}

1. Electrical Engineering, King Fahd University of Petroleum and Minerals, Saudi Arabia, K. O. Akande, T. O. Owolabi, S. Twaha, and S. O. Olatunji, "Performance Comparison of SVM and ANN in Predicting Compressive Strength of Concrete," IOSRJCE, vol. 16, no. 5, pp. 88-94, 2014.

2. K. Kersting, "Machine Learning and Artificial Intelligence: Two Fellow Travelers on the Quest for Intelligent Behavior in Machines," Front. Big Data, vol. 1, p. 6, Nov. 2018.

3. N. R. Washburn, A. Menon, C. M. Childs, B. Poczos, and K. E. Kurtis, "Machine Learning Approaches to Admixture Design for Clay-Based Cements," in Calcined Clays for Sustainable Concrete, vol. 16, F. Martirena, A. Favier, and K. Scrivener, Eds. Dordrecht: Springer Netherlands, 2018, pp. 488-493.

4. A. Voulodimos, N. Doulamis, A. Doulamis, and E. Protopapadakis, "Deep Learning for Computer Vision: A Brief Review," Computational Intelligence and Neuroscience, vol. 2018, pp. 1-13, 2018.

5. M. A. Anusuya and S. K. Katti, "Speech Recognition by Machine: A Review," vol. 6, no. 3, p. 25, 2009. 
6. D. W. Otter, J. R. Medina, and J. K. Kalita, "A Survey of the Usages of Deep Learning in Natural Language Processing," arXiv:1807.10854 [cs], Jul. 2018.

7. A. Baldominos, I. Blanco, A. J. Moreno, R. Iturrarte, Ó. Bernárdez, and C. Afonso, "Identifying Real Estate Opportunities using Machine Learning," Applied Sciences, vol. 8, no. 11, p. 2321, Nov. 2018.

8. P. F. S. Silva and G. F. Moita, "A Comparative Study of Machine Learning Methods for Compressive Strength of Concrete," presented at the The 4th World Congress on Civil, Structural, and Environmental Engineering, 2019.

9. M. J. Mwiti, T. J. Karanja, and W. J. Muthengia, "Properties of activated blended cement containing high content of calcined clay," Heliyon, vol. 4, no. 8, p. e00742, Aug. 2018.

10. A. M. Neville, Properties of concrete, 4th and final ed., reprint. Harlow, Essex: Longman, 1997.

11. H. Chen, C. Qian, C. Liang, and W. Kang, "An approach for predicting the compressive strength of cement-based materials exposed to sulfate attack," PLOS ONE, vol. 13, no. 1, p. e0191370, Jan. 2018.

12. D. Dao, H.-B. Ly, S. Trinh, T.-T. Le, and B. Pham, "Artificial Intelligence Approaches for Prediction of Compressive Strength of Geopolymer Concrete," Materials, vol. 12, no. 6, p. 983, Mar. 2019.

13. Department of Civil and Environmental Engineering, University of Alberta, Edmonton, Canada, N. B.

Siraj, A. R. Fayek, and A. A. Tsehayae, "Development and Optimization of Artificial Intelligence-Based Concrete Compressive Strength Predictive Models," IJSCER, 2016.

14. P. Sihag, M. Kumar, and V. Singh, "Enhanced soft computing for ensemble approach to estimate the compressive strength of high strength concrete," p. 11, 2019.

15. S. Chowdhury, A. Maniar, and O. M. Suganya, "Strength development in concrete with wood ash blended cement and use of soft computing models to predict strength parameters," Journal of Advanced Research, vol. 6, no. 6, pp. 907-913, Nov. 2015.

16. P. F. S. Silva and G. F. Moita, "A Comparative Study of Machine Learning Methods for Compressive Strength of Concrete," presented at the The 4th World Congress on Civil, Structural, and Environmental Engineering, 2019.

17. B. A. Omran, Q. Chen, and R. Jin, "Prediction of Compressive Strength of 'Green' Concrete Using Artificial Neural Networks," p. 8, 2014.

18. J. M. Wachira, J. K. Thiong'o, J. M. Marangu, and L. G. Murithi, "Physicochemical Performance of Portland-Rice Husk Ash-Calcined Clay-Dried Acetylene Lime Sludge Cement in Sulphate and Chloride Media," Advances in Materials Science and Engineering, vol. 2019, pp. 1-12, Apr. 2019.

19. J. M. Marangu, J. K. Thiong'o, and J. M. Wachira, "Chloride Ingress in Chemically Activated Calcined Clay-Based Cement," Journal of Chemistry, vol. 2018, pp. 1-8, 2018.

20. S. Chowdhury, A. Maniar, and O. M. Suganya, "Strength development in concrete with wood ash blended cement and use of soft computing models to predict strength parameters," Journal of Advanced Research, vol. 6, no. 6, pp. 907-913, Nov. 2015.

21. B. Wu and G. Ye, "Development of porosity of cement paste blended with supplementary cementitious materials after carbonation," Construction and Building Materials, vol. 145, pp. 52-61, Aug. 2017.

22. Y.-Y. Kim, K.-M. Lee, J.-W. Bang, and S.-J. Kwon, "Effect of W/C Ratio on Durability and Porosity in Cement Mortar with Constant Cement Amount," Advances in Materials Science and Engineering, vol. 2014, pp. $1-11,2014$.

23. J. M. Marangu, J. K. Thiong'o, and J. M. Wachira, "Review of Carbonation Resistance in Hydrated Cement Based Materials,” Journal of Chemistry, vol. 2019, pp. 1-6, Jan. 2019. 